\title{
Een $\alpha$-adrenerge receptorantagonist als behandeling van blaasontledigingsklachten bij vrouwen: Feit of fictie?
}

\author{
Marlous L. E. Vermeulen ${ }^{1} \cdot$ Kevin L. J. Rademakers ${ }^{2}$. Cees van de Beek ${ }^{3}$
}

Published online: 10 January 2018

(c) The Author(s) 2018.

\section{Samenvatting}

De behandeling van blaasontledigingsklachten bij vrouwen bestaat momenteel uit bekkenbodemfysiotherapie en intermitterende zelfkatheterisatie. Dit artikel betreft de effectiviteit van een $\alpha_{1}$-adrenerge receptorantagonist bij deze vrouwen. Hiertoe hebben wij gekeken naar de recente literatuur en de uitkomst van 11 klinische studies. De resultaten van de verschillende studies laten zien dat bij de interventiegroep de International Prostate Symptoms Score (IPSS), evenals de $\mathrm{Q}_{\max }$ en de, $\mathrm{P}_{\mathrm{det}} \mathrm{Q}_{\max }$ significant verbeteren en het residu significant vermindert. In de onderzoeken met een placebogroep verbeterden de urodynamische parameters echter niet significant. Mede gezien de in-vitro-effectiviteit, het minimale bijwerkingenprofiel en de huidige bewijskracht, valt bij vrouwen met blaasontledigingsklachten behandeling met een $\alpha_{1}$-adrenerge receptorantagonist te overwegen. De bewijskracht hiervoor is echter matig, mede door de uiteenlopende uitkomstmaten in de verschillende studies en het ontbreken van voldoende gerandomiseerde studies.

Trefwoorden blaasontledigingsklachten $\cdot$ vrouwen $\cdot \alpha_{1}$-adrenerge receptorantagonist

\section{An $\alpha$-adrenerg receptor antagonist as treatment of bladder outflow obstruction in women: Fact or fiction?}

\begin{abstract}
At present, the treatment of bladder outflow obstruction (BOO) in women is limited to pelvic floor physiotherapy or intermittent self-catheterization. The goal of this article is to explore the effectivity of an $\alpha_{1}$-adrenergic receptor antagonist for these women. For this, we looked at the literature and included eleven clinical trials. Comparing results shows consistent significant improvement in IPSS, the $\mathrm{Q}_{\max }, \mathrm{P}_{\mathrm{det}} \mathrm{Q}_{\max }$ and residual volume after micturition in the intervention group. However, there are no significant differences in urodynamic outcome parameters between the intervention and placebo group. Based on the in vitro results, the minimal side effects and the suggested clinical effectiveness, an $\alpha_{1}$-adrenergic receptor antagonist is an option to consider in women with BOO. However, the current quality of evidence is moderate, because of the diversity in outcome measures and the absence of multiple randomized trials.
\end{abstract}

Keywords bladder outflow obstruction $\cdot$ female $\cdot \alpha_{1}$-adrenergic receptor antagonist

drs. Marlous L. E. Vermeulen

marlous.vermeulen@gmail.com

1 afdeling Urologie, Zuyderland Medisch Centrum, Sittard, Nederland

2 afdeling Urologie, Zuyderland Medisch Centrum, Heerlen, Nederland

3 afdeling Urologie, Maastricht Universitair Medisch Centrum, Maastricht, Nederland 


\section{Introductie}

Klachten van de lage urinewegen (lower urinary tract symptoms (LUTS)) bij vrouwen zijn een onderbelicht thema binnen de algemene urologie. In de bestaande literatuur over dit onderwerp wordt met name gesproken over blaasvullingsklachten en minder over blaasontledigingsklachten. Echter, op het Pelvic Care spreekuur in het Maastricht Universitair Medisch Centrum presenteert ongeveer $30 \%$ van de vrouwen zich met juist de blaasontlediging als hoofdklacht. De klachten variëren dan van bemoeilijkte mictie, hesitatie, zwakke straal, residugevoel of recidiverende urineweginfecties (UWI) (bij residuen). Een onvolledige evacuatie van de blaas kan bij deze vrouwen leiden tot een retentieblaas, met in enkele gevallen nierfalen als gevolg.

Problemen met blaasontlediging bij vrouwen kunnen berusten op een anatomische of functionele blaas outflow obstructie (BOO) of op detrusor-onderactiviteit (DO). Bij blaasontledigingsklachten door DO, is sprake van een disfunctie van de blaas(spier) bij een aantoonbaar normale urethrale weerstand. Men spreekt van een anatomische BOO als de blaasontlediging gehinderd wordt door bijvoorbeeld een prolaps of meatusstenose. Een anatomische BOO kan echter ook iatrogeen zijn, zoals (tijdelijk) na het plaatsen van een mid-urethrale sling. Een functionele BOO wordt veroorzaakt door inadequate relaxatie van de bekkenbodemspieren. Voor vrouwen bij wie geen anatomische obstructie gevonden wordt of bij wie operatief ingrijpen onwenselijk is, blijven weinig behandelopties over. Bekkenbodemfysiotherapie is niet altijd effectief en indien de mictieklachten aanleiding geven tot residuen, is zelfkatheterisatie uiteindelijk de enig overblijvende behandeling. Zelfkatheterisatie is echter niet bij iedere patiënte gewenst of mogelijk.

Bij de behandeling van blaasontledigingsklachten bij vrouwen is op dit moment nog nauwelijks ruimte voor medicatie. Mannen met blaasontledigingsklachten op basis van benigne prostaatvergroting (BPE) worden daarentegen veelvuldig medicamenteus behandeld. Conform de EAUrichtlijn Treatment of non-neurogenic Male LUTS kan een $\alpha_{1}$-adrenerge receptorantagonist, zoals tamsulosine, worden gestart om de blaashals en urethra prostatica deels te relaxeren [1].

Verscheidene studies hebben angetoond dat ook de vrouwelijke urethra $\alpha_{1}$-receptoren bevat [2-4]. Uit invitro-onderzoeken bij vrouwtjeskonijnen blijkt dat er middels stimulatie van deze $\alpha_{1}$-receptoren door noradrenalinereceptorantagonist in de urethra een rustspanning wordt gewaarborgd. Een $\alpha_{1}$-adrenerge receptorantagonist vermindert in deze onderzoeken de urethrale druk [5,6]. Dit is ook aangetoond in een dierstudie met vrouwtjeshonden en in een studie met gezonde vrouwelijke proefpersonen [7, 8].
Een $\alpha_{1}$-adrenerge receptorantagonist zou dus theoretisch gezien, de mictie kunnen vergemakkelijken door afname van de urethrale weerstand. Of een $\alpha_{1}$-adrenerge receptorantagonist in de kliniek werkzaam is bij vrouwen met blaasontledigingsklachten is nog onduidelijk; de urethra is immers kort, en bij de mictie van de vrouw spelen ook de bekkenbodemspieren een significante rol. Daarbij zal het effect van $\alpha_{1}$-adrenerge receptorantagonisten bij patiënten met BOO en met DO mogelijk verschillen, omdat de rol van de $\alpha_{1}$-adrenerge receptor bij DO nog niet volledig duidelijk is.

Doel van dit artikel is de bewijskracht te inventariseren voor de behandeling van blaasontledigingsklachten bij vrouwen met $\alpha_{1}$-adrenerge receptorantagonisten, deze bewijskracht samen te vatten en een aanbeveling te doen voor de dagelijkse praktijk.

\section{Materiaal en methode}

Voor dit artikel hebben wij gezocht in PubMed met de zoektermen $\alpha$-blockers' [AND] 'female' [OR] 'women' [AND] 'lower urinary tract symptoms'. Daarna zijn de Engelstalige artikelen geselecteerd over studies naar de behandeling van vrouwen met blaasontledigingsklachten met een $\alpha_{1}$ adrenerge receptorantagonist. Artikelen waarin met name blaasvullingsklachten centraal stonden, zijn geëxcludeerd. $\mathrm{Er}$ is ook gekeken naar de referenties van de geselecteerde artikelen.

Wij vonden 11 studies waarin een $\alpha_{1}$-adrenerge receptorantagonist werd toegepast als interventie bij vrouwelijke patiënten met blaasontledigingsklachten: zes prospectieve onderzoeken en vijf gerandomiseerde klinische studies (RCT's), waarvan er drie placebogecontroleerd waren. Ook vonden wij één review.

\section{Onderzoekspopulatie}

De 1.032 vrouwen uit de geselecteerde artikelen waren gemiddeld 25,3-63,8 jaar en hadden allen een bepaalde vorm van mictieklachten. De diagnoses en de inclusiecriteria waren echter zeer divers (tab. 1). In de meeste publicaties betrof het patiënten met LUTS met de diagnose BOO, die werd gedefinieerd als een $\mathrm{Q}_{\max }$ (maximale flowsnelheid) $<12$ of $15 \mathrm{ml} / \mathrm{s}$ en/of een $\mathrm{P}_{\text {det }} \mathrm{Q}_{\max }$ (detrusordruk tijdens de $\left.\mathrm{Q}_{\max }\right)>20 \mathrm{cmH}_{2} \mathrm{O}$ (lage flow en hoge druk). In sommige studies vond inclusie enkel plaats op basis van de International Prostate Symptoms Score (IPSS) $>8$. Het residu na mictie werd op verschillende manieren als inclusiecriteria gebruikt. Twee artikelen baseerden hun diagnose BOO op het mictiecystogram. Eén artikel includeerde ook patiënten met DO, dat werd gedefinieerd als $\mathrm{Q}_{\max } \leq 15 \mathrm{ml} / \mathrm{s}$ en een $\mathrm{P}_{\mathrm{det}} \mathrm{Q}_{\max }<20 \mathrm{cmH}_{2} \mathrm{O}$ (lage flow en lage druk). De follow- 


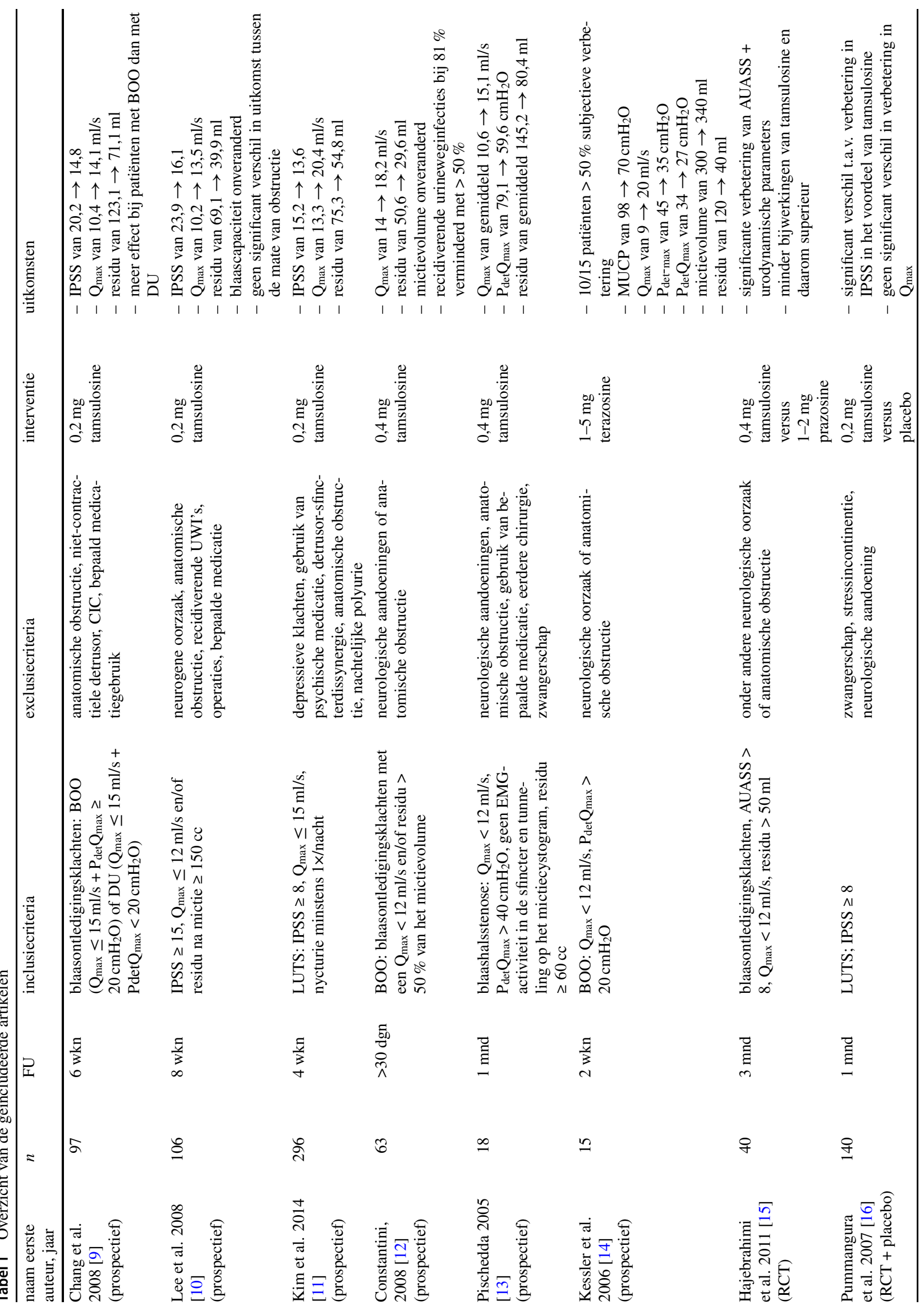




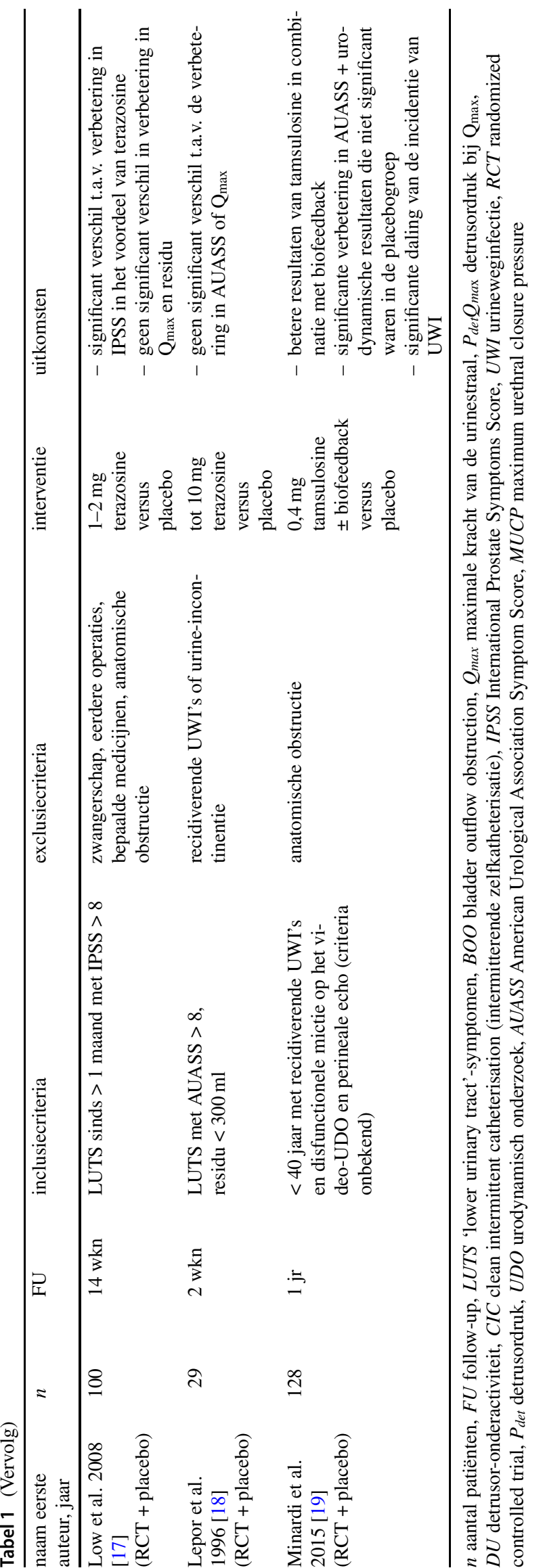

up varieerde van 4 weken $t / m 1$ jaar en de onderzoekspopulaties liepen uiteen van $15 \mathrm{t} / \mathrm{m} 364$ patiënten.

\section{Interventie}

De interventie bestond in 8 van de 11 artikelen uit tamsulosine, dan wel in combinatie, dan wel in vergelijking met een ander middel (prazosine) of behandelmethode (biofeedback). De dosering van tamsulosine varieerde van $0,2-0,4 \mathrm{mg}$. Drie artikelen gebruikten terazosine als interventie in een dosering van $1-10 \mathrm{mg}$.

\section{Uitkomstmaten}

Het effect van de $\alpha_{1}$-adrenerge receptorantagonist werd uitgedrukt als de IPSS of de American Urological Association Symptom Score (AUASS), en de $\mathrm{Q}_{\max }$, de $\mathrm{P}_{\mathrm{det}}$, de $\mathrm{P}_{\mathrm{det}} \mathrm{Q}_{\max }$, de urethrale druk, het residu na mictie en de blaascapaciteit, dan wel het mictievolume, zoals beschreven in tab. 1 .

\section{Resultaten}

Drie prospectieve onderzoeken keken naar de verbetering in de IPSS na behandeling met $0,2 \mathrm{mg}$ tamsulosine. Er werd een significante daling gevonden van gemiddeld 5 punten [9-11]. Urodynamisch gezien leidde in alle prospectieve onderzoeken tamsulosine tot een significante verbetering van de $\mathrm{Q}_{\max }$ met 3,3-7,1 ml/s, en in de studie waarin 1-5 mg terazosine werd gegeven zelfs met $11,1 \mathrm{ml} / \mathrm{s}$ [9-14]. De $\mathrm{P}_{\text {det }} \mathrm{Q}_{\max }$ werd in twee prospectieve studies onderzocht en daalde in de ene studie met $10 \mathrm{cmH}_{2} \mathrm{O}$ en in de andere studie met $20 \mathrm{cmH}_{2} \mathrm{O}[13,14]$. Het residu na mictie nam met circa een derde af, terwijl het mictievolume nagenoeg gelijk bleef. Subjectief had $84 \%$ van de vrouwen baat bij de behandeling [10]. In één studie, waarin onderscheid werd gemaakt tussen blaasontledigingsklachten door DO of door $\mathrm{BOO}$, werd geconcludeerd dat de patiënten met $\mathrm{BOO}$ meer baat hebben bij de behandeling dan de patiënten met DO [9]. De mate van obstructie, gemeten met de $\mathrm{P}_{\mathrm{det}} \mathrm{Q}_{\max }$ ten opzicht van de $\mathrm{Q}_{\max }$, had geen invloed op de effectiviteit van de $\alpha_{1}$-adrenerge receptorantagonist [10].

In de vijf RCT's [15-19] werden vergelijkbare verbeteringen beschreven, maar in vier van de vijf van RCT's met een placebogroep verbeterden niet alle uitkomstmaten significant [16-19]. In de studie van Lepor en Theune verbeterde de AUASS bijvoorbeeld niet significant [18]. Minardi et al. vonden op de AUASS wel een significant verschil, maar hun onderzoekspopulatie bestond uit patiënten met recidiverende urineweginfecties en een disfunctionele mictie in plaats van LUTS, en een AUASS die al bij inclusie hoger was [19]. In de twee andere RCT's, waarin patiënten middels de IPSS werden gevolgd, werd wel een 
significante verschil in daling op die score aangetoond in het voordeel van de interventiegroep [16, 17]. De urodynamische onderzoeken toonden echter in drie van de vier placebogecontroleerde trials geen significant verschil, maar wel in het artikel met de langste follow-up (1 jaar) [19].

Een review uit 2014 met 14 prospectieve onderzoeken en één retrospectief onderzoek benadrukte reeds de mogelijke effectiviteit van $\alpha_{1}$-adrenerge receptorantagonisten (tamsulosine, terazosine, prazosine of alfuzosine) bij vrouwen met LUTS [20]. Hierbij moet worden vermeld dat het in deze studies zowel blaasvullingsklachten als -ontledigingsklachten betrof.

\section{Discussie}

Zoals hiervoor beschreven, lopen de inclusiecriteria in de geselecteerde studies sterk uiteen. Dit komt omdat er nog geen eenduidig definitie is voor blaasontledigingsklachten bij vrouwen [21]. Want hoewel elke onderzoekspopulatie genoemde had, werden er verschillende diagnoses gesteld. Daarmee zijn de uitgangswaarden en dus de resultaten niet met elkaar te vergelijken. Omdat aan blaasontledigingsklachten verschillende oorzaken ten grondslag liggen, liggen ook de onderzoeksresultaten ver uit elkaar.

Daarnaast is het nog onduidelijk wat de klinische effectiviteit is van een $\alpha_{1}$-adrenerge receptorantagonist bij vrouwen met blaasontledigingsklachten. $\mathrm{Er}$ is namelijk in de prospectieve onderzoeken wel een significante verbetering ten aanzien van de urodynamische resultaten, maar of de patiënten daarmee dan ook voldoende geholpen zijn, blijft onduidelijk. De subjectieve klachten verbeteren significant bij gebruik van een $\alpha_{1}$-adrenerge receptorantagonist, maar het is niet zeker of het ook een interventie is om intermitterend katheteriseren te voorkomen als er sprake is van een aanzienlijk residu. Het residu na mictie verbetert dan wel in alle prospectieve onderzoeken significant, maar de omvang van het residu was zowel voor als na de interventie rond de $100 \mathrm{cc}$, dus er bestaat twijfel over de klinische significantie van dit resultaat.

Als laatste valt nog te benoemen dat de placebogecontroleerde onderzoeken andere resultaten laten zien dan de prospectieve onderzoeken. De urodynamische resultaten verbeteren in de eerste onderzoeken namelijk niet significant ten opzichte van de placebogroep. De urodynamische waarden behoorden in de RCT's echter niet tot de inclusiecriteria en lagen in de RCT's bovendien aanzienlijk hoger dan in de prospectieve onderzoeken. Er wordt wel een significant verschil gezien in de IPSS, maar de IPSS is niet gevalideerd voor LUTS bij vrouwen. Dus zowel de huidige prospectieve onderzoeken als de RCT's zijn van onvoldoende kwaliteit om voldoende bewijskracht te leveren voor een $\alpha_{1}$-adrenerge receptorantagonist bij vrouwen met blaasontledigingsklachten.

\section{Conclusie}

Uit de resultaten van de onderzochte artikelen valt te concluderen dat de $\alpha_{1}$-adrenerge receptorantagonist, mede door de uiteenlopende inclusiecriteria en uitkomstmaten in de verschillende studies, nog altijd fictie is bij de behandeling van vrouwen met blaasontledigingsklachten. Er is onvoldoende bewijskracht om de vermeende effectiviteit aan te tonen. Eensgezindheid hierover en nieuwe gerandomiseerde placebogecontroleerde studies met homogene patiëntengroepen en een follow-up die voldoende lang is, zijn nodig om vast te kunnen stellen of de effectiviteit van een $\alpha_{1}$-adrenerge receptorantagonist voor vrouwen met blaasontledigingsklachten een feit is. Ondanks de huidige matige bewijskracht is off-labelgebruik van een $\alpha_{1}$-adrenerge receptorantagonist te overwegen bij vrouwen met blaasontledigingsklachten, bij wie bekkenbodemfysiotherapie onvoldoende effect heeft, in een poging intermitterende zelfkatheterisatie uit te stellen of te voorkomen, mede gezien het minimale bijwerkingenprofiel van dit middel.

Open Access This article is distributed under the terms of the Creative Commons Attribution 4.0 International License (http:// creativecommons.org/licenses/by/4.0/), which permits unrestricted use, distribution, and reproduction in any medium, provided you give appropriate credit to the original author(s) and the source, provide a link to the Creative Commons license, and indicate if changes were made.

\section{Literatuur}

1. Oelke M, Bachmann A, Descazeaud A, et al. EAU Guideline on the treatment and follow-up of non-neurogenic male lower urinary tract symptoms including benign prostatic obstruction. Eur Urol. 2013;64:118-40.

2. Nasu K, Moriyama N, Fukasawa R, et al. Quantification and distribution of $\alpha_{1}$-adrenoceptor subtype mRNAs in human proximal urethra. Br J Pharmacol. 1998;123:1289-93.

3. Alberts P, Bergström PAC, Fredrickson G. Characterision of the functional $\alpha$-adrenoceptor subtype in the isolated female pig urethra. Eur J Pharmacol. 1999;371:31-8.

4. Canda AE, Cinar MG, Turna B, Sahin MO. Pharmacologic targets on the female urethra. Urol Int. 2008;80:341-54.

5. Taki N, Taniguchi T, Okada K, et al. Evidence for predominant mediation of $\alpha_{1}$-adrenoceptor in the tonus of entire urethra of women. J Urol. 1999;162:1829-32.

6. Andersson KE, Larsson B, Sjögren C. Characterization of the $\alpha$-adrenoceptors in the female rabbit urethra. $\mathrm{Br} \mathrm{J}$ Pharmacol. 1984;81:293-300.

7. Ohtake A, Sato S, Sasamata M, Miyata K. Effects of tamsulosine on resting urethral pressure and arterial blood pressure in anaesthetized female dogs. J Pharm Pharmacol. 2006;58:345-50.

8. Reitz A, Haferkamp A, Kyburz T, et al. The effect of tamsulosin on the resting tone and the contractile behavior of the female ure- 
thra: a functional urodynamic study in healthy women. Eur Urol. 2004;46:235-40.

9. Chang SJ, Chiang IN, Yu HJ. The effectiveness of tamsulosin in treating women with voiding difficulty. Int J Urol. 2008;15:981-5.

10. Lee KS, Han DH, Lee YS, et al. Efficacy and safety of tamsulosin for the treatment of non-neurogenic voiding dysfunction in females: a 8-week prospective study. J Korean Med Sci. 2010;25:117-22.

11. Kim SO, Choi HS, Kwon D. The $\alpha 1$-adrenoceptor antagonist tamsulosin for the treatment of voiding symptoms improves nocturia and sleep quality in women. Urol J. 2014;11:1636-41.

12. Constantini E, Lazzeri M, Bini V, et al. Open-label, longitudinal study of tamsulosin for functional bladder outlet obstruction in women. Urol Int. 2009;83:311-5.

13. Pischedda A, Pirozzi Farina F, et al. Use of a-blockers in female functional bladder neck obstruction. Urol Int. 2005;74:256-61.

14. Kessler TM, Studer UE, Burkhard FC. The effect of terazosin on functional bladder outlet obstruction in women: a pilot study. J Urol. 2006;176:1487-92.

15. Hajebrahimi S, Asrbadr YA, Azaripour A, Sadeghi-Bazargani H. Effect of tamsulosine versus prazosin on clinical and urodynamic parameters in women with voiding difficulty: a randomized clinical trial. Int J Gen Med. 2011;4:35-9.

16. Pammangura N, Kochakarn W. Efficacy of tamsulosin in the treatment of lower urinary tract symptoms (LUTS) in women. Asian J Surg. 2007;30:131-7.
17. Low BY, Liong ML, Yuen KH, et al. Terazosin therapy for patients with female lower urinary tract symptoms: a randomized, doubleblind, placebo controlled trial. J Urol. 2008;179:1461-9.

18. Lepor H, Theune C. Randomized double-blind study comparing the efficacy of terazosin versus placebo in women with prostatism-like symptoms. J Urol. 1995;154:116-8.

19. Minardi D, Pellegrinelli F, Conti A, et al. $\alpha_{1}$-blockers for the treatment of recurrent urinary tract infections in women with dysfunctional voiding: a prospective randomized study. Int J Urol. 2015;22:115-21.

20. Boyd K, Hilas O. $\alpha$-Adrenergic blockers for the treatment of lowerurinary-tract symptoms and dysfunction in women. Ann Pharmacother. 2014;48:711-22.

21. Gammie A, Kirschner-Hermanns R, Rademakers K. Evaluation of obstructed voiding in the female: how close are we to a definition? Curr Opin Urol. 2015;25:292-5.

drs. Marlous L.E. Vermeulen anios urologie

drs. Kevin L.J. Rademakers aios urologie

drs. Cees van de Beek uroloog 
Hier steht eine Anzeige.

Springer 